\title{
Liquid Chromatography-tandem Mass Spectrometry for Quantification of Dioscin in Rat Plasma
}

\author{
Tae Yeon Kong ${ }^{\mathrm{a}}$, Hye Young $\mathrm{Ji}^{\mathrm{a}}$, Sang-Zin Choi ${ }^{\mathrm{b}}$, Miwon Son ${ }^{\mathrm{b}}$, and Hye Suk Lee ${ }^{\mathrm{a}^{*}}$ \\ ${ }^{a}$ Drug Metabolism and Bioanalysis Laboratory, College of Pharmacy, The Catholic University of Korea, Bucheon, 420-743, Korea \\ ${ }^{b}$ Research Center, Donga ST Co., Yongin 446-905, Korea
}

Received September 16, 2013; Revised September 25, 2013; Accepted September 25, 2013

First published on the web September 30, 2013; DOI: 10.5478/MSL.2013.4.3.55

\begin{abstract}
Dioscin is a biologically active steroidal saponin with anticancer and hepatoprotective effects. A rapid, selective, and sensitive liquid chromatographic method with electrospray ionization tandem mass spectrometry was developed for the quantification of dioscin in rat plasma. Dioscin was extracted from rat plasma using ethyl acetate at acidic $\mathrm{pH}$. The analytes were separated on a Halo C18 column using gradient elution of acetonitrile and $0.1 \%$ formic acid and detected by tandem mass spectrometry in selected reaction monitoring mode. The standard curve was linear $\left(r^{2}=0.998\right)$ over the concentration range of $1-100 \mathrm{ng} / \mathrm{mL}$. The lower limit of quantification was $1.0 \mathrm{ng} / \mathrm{mL}$ using $50 \mu \mathrm{L}$ of plasma sample. The coefficient of variation and relative error for intra- and inter-assay at four QC levels were 1.3 to $8.0 \%$ and -5.4 to $10.0 \%$, respectively. This method was applied successfully to the pharmacokinetic study of dioscin after oral administration of dioscin at a dose of $29.2 \mathrm{mg} / \mathrm{kg}$ in male Sprague-Dawley rats.
\end{abstract}

KeyWords: Dioscin; LC-MS/MS; Rat plasma

\section{Introduction}

Dioscin, isolated from Dioscorea nipponica Makino and Dioscorea villosa, ${ }^{1}$ has hepatoprotective, ${ }^{2-4}$ antifungal, ${ }^{5}$ and anticancer ${ }^{6-10}$ effects. It is necessary to evaluate pharmacokinetics of dioscin in order to develop dioscin as a possible new therapeutic treatment for cancer. ${ }^{11}$

Due to its selectivity, sensitivity, robustness, and sample throughput, liquid chromatography/tandem mass spectrometry (LC-MS/MS) is recognized as a powerful tool for use in quantification of active compounds of herbal drugs in biological samples. ${ }^{11-14}$ There were few reports on bioanalytical methods for the determination of dioscin in rat biological fluids using LC-MS/MS method with protein precipitation method as sample clean-up procedure. ${ }^{15-17}$ Sample preparation was important to rem-ove the endogenous interferences from herbal drug and plasma.

The purpose of this paper was to develop a rapid, selective, and sensitive LC-MS/MS assay using liquidliquid extraction as sample preparation procedure for quantification of dioscin in rat plasma. This method was applied successfully to the pharmacokinetic study of dioscin after oral administration of dioscin in male Sprague-Dawley rats.

\footnotetext{
*Reprint requests to Prof. Hye Suk Lee
}

E-mail: sianalee@catholic.ac.kr

\section{Experimental}

\section{Materials and reagents}

Dioscin (purity, 92\%) and chlorzoxazone (purity, 99.0\%; internal standard) were obtained from PhytoLab $\mathrm{GmbH} \&$ Co. KG (Vestenbergsgreuth, Germany) and Sigma-Aldrich Chemical (St. Louis, MO, USA), respectively. Acetonitrile and ethyl acetate (MS grade) were obtained from Fisher Scientific Co. (Pittsburgh, PA, USA). Other chemicals used were of the highest quality available. Drug-free rat plasma containing sodium heparin as the anticoagulant was obtained from male Sprague-Dawley rats.

\section{Preparation of calibration standards and quality control samples \\ Primary stock solutions of dioscin and chlorzoxazone $(1 \mathrm{mg} / \mathrm{mL})$ were prepared in dimethylsulfoxide. Working standard solutions of dioscin were prepared by dilution of primary stock solution with acetonitrile. The internal standard working solution $(500 \mathrm{ng} / \mathrm{mL}$ chlorzoxazone) was prepared by dilution of an aliquot of stock solution with acetonitrile. All standard solutions were stored at $4^{\circ} \mathrm{C}$ for 4 weeks in $1.5 \mathrm{~mL}$ polypropylene tubes in the dark when not in use. Rat plasma calibration standards of dioscin, i.e., 1, 2, 4, 20, 40, 80, and $100 \mathrm{ng} / \mathrm{mL}$, were prepared by addition of $2.5 \mu \mathrm{L}$ of the working standard solutions $(0.02,0.04,0.08,0.4,0.8,1.6$, and $2 \mu \mathrm{g} / \mathrm{mL}$ ) to $50 \mu \mathrm{L}$ of drug-free rat plasma. Quality control (QC) samples at $1,3.5,35$, and $75 \mathrm{ng} / \mathrm{mL}$ were prepared in bulk by addition of $25 \mu \mathrm{L}$ of the appropriate working standard}


solutions $(0.2,0.7,7$, and $15 \mu \mathrm{g} / \mathrm{mL})$ to drug-free rat plasma $(4950 \mu \mathrm{L})$. Bulk samples were aliquoted $(50 \mu \mathrm{L})$ into polypropylene tubes and stored at $-80^{\circ} \mathrm{C}$ until analysis.

\section{Sample preparation}

Fifty $\mu \mathrm{L}$ of rat blank plasma, calibration standards, and QC samples were mixed with $200 \mu \mathrm{L}$ of $50 \mathrm{mM}$ ammonium formate buffer ( $\mathrm{pH} 3.0), 5 \mu \mathrm{L}$ of chlorzoxazone in acetonitrile (I.S., $500 \mathrm{ng} / \mathrm{mL}$ ), and $1000 \mu \mathrm{L}$ of ethyl acetate by using vortex mixer for $2 \mathrm{~min}$. After centrifugation at $13000 \mathrm{rpm}$ for 5 min, the supernatants $(900 \mu \mathrm{L})$ were transferred in new polypropylene tubes. The aqueous layers were extracted once more with $1000 \mu \mathrm{L}$ of ethyl acetate and the supernatants $(900 \mu \mathrm{L})$ were transferred after centrifugation. The organic layer was evaporated to dryness at $35^{\circ} \mathrm{C}$ for $30 \mathrm{~min}$ by using vacuum evaporator. The residues were dissolved in $60 \mu \mathrm{L}$ of $55 \%$ acetonitrile and were sonicated for $2 \mathrm{~min}$. After centrifugation, the aliquot $(2 \mu \mathrm{L})$ was injected on UPLC and analyzed by LC-MS/MS system.

\section{LC-MS/MS Analysis}

The LC-MS/MS system consisted of an Agilent 1200 series (Agilent Technologies, Wilmington, DE, USA) and a 6490 triple quadrupole mass spectrometer (Agilent Technologies). Separation was performed on a Halo C18 $(2.7 \mu \mathrm{m}, 2.1 \mathrm{~mm}$ i.d. x $50 \mathrm{~mm}$, Advanced materials technology, Wilmington, DE, USA) using gradient elution of $5 \%$ acetonitrile $0.1 \%$ formic acid (mobile phase A) and 95\% acetonitrile in $0.1 \%$ formic acid (mobile phase B) at a flow rate of $0.40 \mathrm{~mL} / \mathrm{min}$ : $10 \%$ mobile phase $\mathrm{B}$ for $0.5 \mathrm{~min}, 10 \%$ to $80 \%$ mobile phase $\mathrm{B}$ for $1.5 \mathrm{~min}, 80 \%$ mobile phase B for $1.0 \mathrm{~min}, 80 \%$ to $10 \%$ mobile phase $\mathrm{B}$ for $0.1 \mathrm{~min}, 10 \%$ mobile phase $\mathrm{B}$ for $1.9 \mathrm{~min}$. The column and autosampler were maintained at $40^{\circ} \mathrm{C}$ and $10^{\circ} \mathrm{C}$, respectively. ESI source settings for ionization of dioscin and chlorzoxazone in the negative mode were as follows: capillary voltage, $-3000 \mathrm{~V}$; gas temperature, $200^{\circ} \mathrm{C}$; heater temperature, $360^{\circ} \mathrm{C}$; sheath gas flow, $11 \mathrm{~L} / \mathrm{min}$. Fragmentation of mole-cular ion for dioscin and chlorzoxazone was performed at a collision energy of $25 \mathrm{eV}$ and $17 \mathrm{eV}$, respectively, using nitrogen gas as a collision gas at a pressure of 2 bar on the instrument. Selected reaction monitoring (SRM) mode was employed for the quantification: $m / z \quad 913.48 \rightarrow 867.3$ for dioscin and $m / z \quad 167.98 \rightarrow 131.9$ for chlorzoxazone. Mass Hunter software (Agilent Technologies) was used for LC-MS/ MS system control and data processing.

\section{Method Validation}

In order to complete the method validation, batches, consisting of triplicate calibration standards at each concentration, were analyzed on three different days. In each batch, QC samples at 1, $3.5,35$, and $75 \mathrm{ng} / \mathrm{mL}$ were assayed in sets of five replicates for evaluation of intra- and inter-day precision and accuracy. The relative error (RE), percentage deviation of the mean from true values, serves as a measure of the accuracy and the coefficient of variation $(\mathrm{CV})$ indicates the precision.
Recovery of dioscin and chlorzoxazone was determined by comparison of mean peak areas of the analytes spiked before extraction into plasma sources with those of the analytes spiked post-extraction into blank plasma extracts at three concentrations, i.e., 3.5, 35, and $75 \mathrm{ng} / \mathrm{mL}$.

For evaluation of room temperature storage and long-term storage at $-80^{\circ} \mathrm{C}$ stability, triplicates of QC samples at low and high concentrations ( 3.5 and $75 \mathrm{ng} / \mathrm{mL}$ ) were subjected to storage at room temperature for $4 \mathrm{~h}$ or at $-80^{\circ} \mathrm{C}$ for 28 days before processing. Post-extraction batch integrity was determined by batch reinjection after $12 \mathrm{~h}$ storage at $10^{\circ} \mathrm{C}$ in the autosampler.

\section{Pharmacokinetic study of dioscin in rats}

Sprague-Dawley rats (body weight 235-255 g, Samtako Co. Osan, Korea) were housed in a temperature controlled room at $22-24^{\circ} \mathrm{C}$ with a $12 \mathrm{~h}$ light/dark cycle and relative humidity of $55 \pm 10 \%$. Rats were cannulated with polyethylene tubing (PE-50, Clay Adams, Parsippany, NJ, USA) in jugular vein under anesthesia with intraperitoneal injection of zoletil $(50 \mathrm{mg} / \mathrm{kg})$. Each rat was housed individually in a rat metabolic cage and allowed to recover from anesthesia for 2 day. The rats were not restrained at any time during the study. Heparinized isotonic saline $(10 \mathrm{U} / \mathrm{mL})$ was used to flush the catheters to prevent blood clotting. The rats were fasted for more than $12 \mathrm{~h}$ before oral administration of drugs.

Dioscin was dissolved in a mixture of dimethylsulfoxide: propylene glycol: deionzied water $(1: 7: 2, v / v)$ and was administered to seven rats by oral gavages at $29.2 \mathrm{mg} / \mathrm{kg}$. Blood samples were collected at 0 (control), 1, 2, 4, 6, 8, 12, 24, 36, 48, 72, 96, and $120 \mathrm{~h}$ after drug administration. Plasma samples were harvested by centrifugation at $3000 \mathrm{xg}$ for 10 min and stored at $-80^{\circ} \mathrm{C}$ until analysis. A noncompartment analysis (WinNonlin, Pharsight, Mountain View, CA, USA) was used for analysis of pharmacokinetic parameters.

\section{Results and Discussion}

Dioscin and chlorzoxazone (internal standard) produced the molecular ions at $m / z 913.48\left(\left[\mathrm{M}+\mathrm{HCOO}^{-}\right)\right.$and $\mathrm{m} / z 167.98$ $\left([\mathrm{M}-\mathrm{H}]^{-}\right)$, respectively, using electrospray ionization with negative mode. MS/MS spectra for dioscin and chlorzoxazone showed the product ions at $\mathrm{m} / \mathrm{z} 867.3$ for dioscin and $\mathrm{m} / \mathrm{z} 131.9$ for chlorzoxazone, respectively (Figure 1). For the quantification of dioscin in plasma samples, SRM mode was used and the transition ions were $\mathrm{m} / \mathrm{z} 913.48$ to $\mathrm{m} / \mathrm{z} 867.3$ for dioscin and $\mathrm{m} / \mathrm{z} 167.98$ to $\mathrm{m} / \mathrm{z} 131.9$ for chlorzoxazone.

After many trials with different columns and mobile phase combinations, dioscin was well separated from the interferences on Halo C18 column compared to RP amide, Cadenza C18, and Unison UKC8 column. Gradient elution of acetonitrile and $0.1 \%$ formic acid as mobile phase resulted in better sensitivity compared to the use of other buffers and methanol.

In the analysis of blank plasma samples obtained from fifteen different rats, no interference peak was observed at the 
retention times of dioscin (3.2 $\mathrm{min})$ and chlorzoxazone (2.5 min), confirming the selectivity of the present method (Figure 2a). Sample carryover effect was not observed.

Calibration curves were obtained over the concentration range of 1 to $100 \mathrm{ng} / \mathrm{mL}$ of dioscin in rat plasma. Linear regression analysis with a weighting of $1 /$ concentration gave
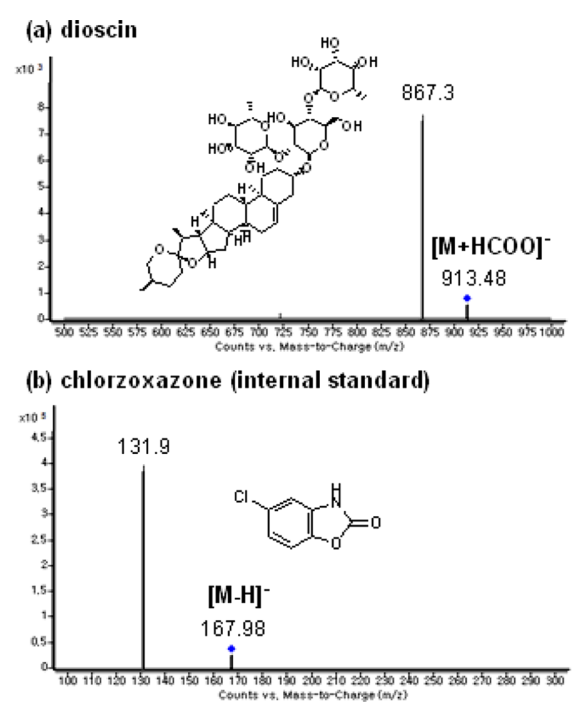

Figure 1. Product ion mass spectra of (a) dioscin and (b) chlorzoxazone (internal standard). the optimum accuracy (RE, -7.5 to $10.0 \%$ ) and precision $(\mathrm{CV}, \leq 12.9 \%)$ of the corresponding calculated concentrations at each level (Table 1). The low CV value (6.9\%) for the slope indicated the repeatability of the method (Table 1 ).

Table 2 shows a summary of intra- and inter-day precision and accuracy data for QC samples containing dioscin. Both intra-and inter-day $\mathrm{CV}$ values ranged from 1.3 to $8.0 \%$ at four QC levels. Intra- and inter-assay RE values were -5.4 to $10.0 \%$ at four QC levels. These results indicated acceptable accuracy and precision of the present method. The lower limit of quantification (LLOQ) for dioscin was set at $1 \mathrm{ng} /$ $\mathrm{mL}$ using $50 \mu \mathrm{L}$ of rat plasma with a signal-to-noise ratio higher than 10 (Figure 2b).

Liquid-liquid extraction using ethyl acetate at acidic $\mathrm{pH}$ showed the acceptable recovery: $74.4( \pm 8.7) \%$ at $3.5 \mathrm{ng} /$ $\mathrm{mL}, 72.5( \pm 12.6) \%$ at $35 \mathrm{ng} / \mathrm{mL}, 76.7( \pm 9.7) \%$ at $75 \mathrm{ng} / \mathrm{mL}$ for dioscin, and $91.0( \pm 5.4) \%$ for chlorzoxazone.

Dioscin was found to be stable in rat plasma for $4 \mathrm{~h}$ storage at room temperature and long-term (28 days) storage at $-80^{\circ} \mathrm{C}$ (Table 3 ). Analysis of the reconstituted extracts stored for $12 \mathrm{~h}$ at $10^{\circ} \mathrm{C}$ showed acceptable accuracy and precision for QC samples of dioscin (Table 3).

This method has been applied successfully to a pharmacokinetic study of dioscin after oral administration of dioscin at a dose of $29.2 \mathrm{mg} / \mathrm{kg}$ in seven male Sprague Dawley rats. Figure 2c shows representative SRM chrom-atograms obtained from analysis of a plasma sample obtained at $2 \mathrm{~h}$ after oral adminis-
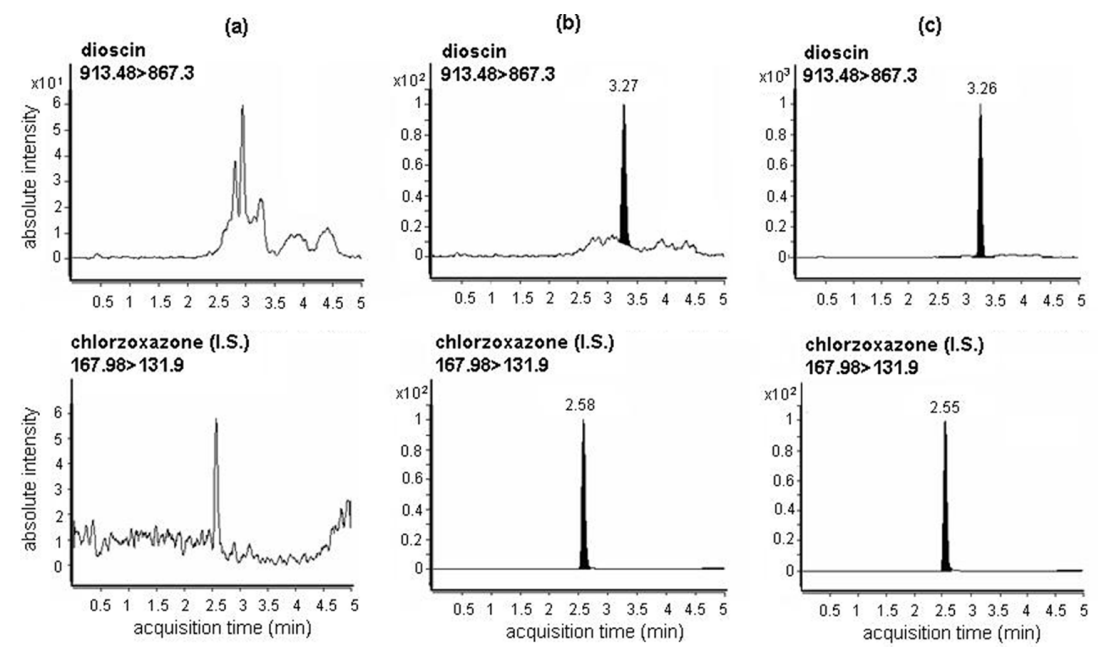

Figure 2. SRM chromatograms of (a) a rat blank plasma, (b) a rat plasma sample spiked with $1 \mathrm{ng} / \mathrm{mL}$ of dioscin, and (c) a rat plasma sample obtained $2 \mathrm{~h}$ after oral administration of dioscin at a dose of $29.2 \mathrm{mg} / \mathrm{kg}$ to a male Sprague-Dawley rat.

Table 1. Calculated concentrations of dioscin in calibration standards prepared in rat plasma $(n=3)$

\begin{tabular}{|c|c|c|c|c|c|c|c|c|c|c|}
\hline \multirow{2}{*}{ Statistical variable } & \multicolumn{7}{|c|}{ "Theoretical concentration (ng/mL) } & \multirow{2}{*}{ slope } & \multirow{2}{*}{ intercept } & \multirow{2}{*}{$r^{2}$} \\
\hline & 1 & 2 & 4 & 20 & 40 & 80 & 100 & & & \\
\hline Mean (ng/mL) & 1.1 & 2.0 & 4.3 & 18.5 & 41.8 & 79.8 & 100.6 & 0.0203 & 0.0058 & 0.998 \\
\hline $\mathrm{CV}(\%)$ & 8.5 & 1.0 & 12.9 & 5.5 & 6.0 & 2.9 & 2.6 & 6.9 & & \\
\hline RE (\%) & 10.0 & 0.0 & 7.5 & -7.5 & 4.5 & -0.3 & 0.6 & & & \\
\hline
\end{tabular}


Table 2. Precision and accuracy of dioscin in quality control samples

\begin{tabular}{ccccccccc}
\hline $\begin{array}{c}\text { Statistical } \\
\text { variable }\end{array}$ & \multicolumn{3}{c}{ Intra-day $(n=5)$} & \multicolumn{4}{c}{ Inter-day $(n=3)$} \\
\hline QC $(\mathrm{ng} / \mathrm{mL})$ & 1 & 3.5 & 35 & 75 & 1 & 3.5 & 35 & 75 \\
Mean $(\mathrm{ng} / \mathrm{mL})$ & 1.1 & 3.8 & 33.1 & 72.9 & 1.1 & 3.4 & 34.9 & 81.0 \\
CV $(\%)$ & 4.6 & 1.6 & 1.6 & 1.3 & 8.0 & 3.8 & 1.6 & 2.6 \\
RE $(\%)$ & 10.0 & 8.6 & -5.4 & -2.8 & 10.0 & -2.9 & -0.3 & 8.0 \\
\hline
\end{tabular}

Table 3. Stability of QC samples $(n=3)$

\begin{tabular}{lcc}
\hline \hline \multirow{2}{*}{ Statistical variable } & \multicolumn{2}{c}{ Theoretical concentration $(\mathrm{ng} / \mathrm{mL})$} \\
\cline { 2 - 3 } & 3.5 & 75 \\
\hline 4 h storage at room temperature & 80.3 \\
\hline Mean $(\mathrm{ng} / \mathrm{mL})$ & 3.5 & 3.9 \\
CV $(\%)$ & 1.4 & 7.0 \\
RE $(\%)$ & 0.0 & \\
\hline Storage at $-80^{\circ}$ C for 28 days & 78.3 \\
\hline Mean $(\mathrm{ng} / \mathrm{mL})$ & 3.7 & 4.3 \\
CV $(\%)$ & 10.1 & 4.4 \\
RE $(\%)$ & 5.7 & 67.3 \\
\hline Post-preparative stability $(12 \mathrm{~h}$ at 10$)$ & 7.2 \\
\hline Mean $(\mathrm{ng} / \mathrm{mL})$ & 3.4 & -10.3 \\
CV $(\%)$ & 8.1 &
\end{tabular}

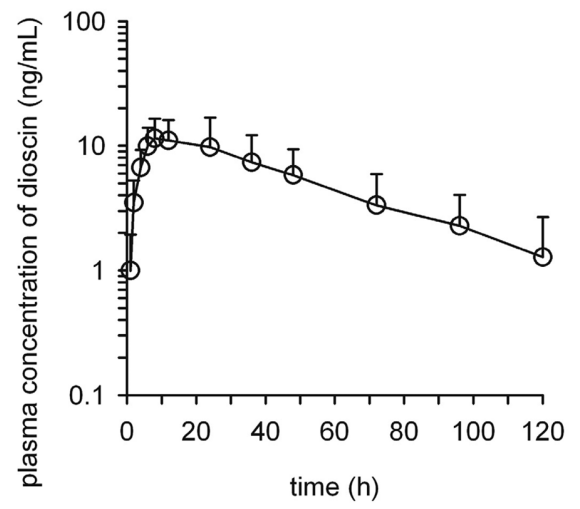

Figure 3. Mean plasma concentration-time plot of dioscin after an oral administration of dioscin at a dose of $29.2 \mathrm{mg} / \mathrm{kg}$ to seven male Sprague-Dawley rats. Each point represents the mean \pm S.D.

tration of dioscin in a rat. The mean plasma concentrationtime plot after oral administration of dioscin in rats is shown in Figure 3. Li et al. ${ }^{16}$ reported that the pharmac-okinetics of diosicn was not evaluated after oral administration of $22.5 \mathrm{mg} / \mathrm{kg}$ was not due to extremely low plasma concentration. After oral administration of dioscin at $29.2 \mathrm{mg} / \mathrm{kg}$, the maximum concentration, the time to maxi-mum concentration, area under the plasma concentrationtime curve, terminal elimination half-life of dioscin were $12.2 \pm 6.0 \mathrm{ng} / \mathrm{mL}, 12.3 \pm 8.0 \mathrm{~h}, 600.5 \pm 372.0 \mathrm{ng} \cdot \mathrm{h} / \mathrm{mL}$, and $45.2 \pm$ $16.0 \mathrm{~h}$, respectively.

\section{Conclusion}

A reliable, selective, and sensitive LC-MS/MS method for quantification of dioscin in rat plasma has been successfully developed. For sample preparation, dioscin and chlorzoxazone were extracted twice from plasma samples using ethyl acetate at acidic $\mathrm{pH}$. Use of the present method demonstrated acceptable selectivity, sensitivity (LLOQ, $1 \mathrm{ng} / \mathrm{mL}$ ), precision, accuracy, and stability. This method was applied successfully to determination of dioscin in rat plasma samples obtained after oral administration of dioscin at a dose of $29.2 \mathrm{mg} / \mathrm{kg}$ in rats.

\section{Acknowledgements}

This work was supported by the Global Leading Technology Program of the Office of Strategic R\&D Planning (OSP), funded by the Ministry of Knowledge Economy (MKE), Republic of Korea (10039303) and the Korea Health Industry Development Institute (KHIDI) grant funded by the Ministry of Health and Welfare, Korea (HI12C1852).

\section{References}

1. Yoon, K. D.; Kim, J. J. Sep. Sci. 2008, 31, 2486.

2. Lu, B.; Yin, L.; Xu, L.; Peng, J. Planta Med. 2011, 77, 407.

3. Lu, B.; Xu, Y.; Xu, L.; Cong, X.; Yin, L.; Li, H.; Peng, J. Environ. Toxicol. Pharmacol. 2012, 34, 127.

4. Zhao, X.; Cong, X.; Zheng, L.; Xu, L.; Yin, L.; Peng, J. Toxicol. Lett. 2012, 214, 69.

5. Cho, J.; Choi, H.; Lee, J.; Kim, M. S.; Sohn, H. Y.; Lee, D. G. Biochim. Biophys. Acta. 2013, 1828, 1153.

6. Wei, Y.; Xu, Y.; Han, X.; Qi, Y.; Xu, L.; Yin, L.; Sun, H.; Liu, K.; Peng, J. Food Chem. Toxicol. 2013, 59, 118.

7. Wang, Z.; Cheng, Y.; Wang, N.; Wang, D. M.; Li, Y. W.; Han, F.; Shen, J. G.; Yang de, P.; Guan, X. Y.; Chen, J. P. Cancer Biol. Ther. 2012, 13, 138.

8. Wang, L.; Meng, Q.; Wang, C.; Liu, Q.; Peng, J.; Huo, X.; Sun, H.; Ma, X.; Liu, K. J. Nat. Prod. 2013, 76, 909.

9. Qin, J.; Kang, Y.; Xu, Z.; Zang, C.; Fang, B.; Liu, X. Drug Res. (Stuttg) 2013, doi: 10.1055/s-0033-1349101.

10. Hu, M.; Xu, L.; Yin, L.; Qi, Y.; Li, H.; Xu, Y.; Han, X.; Peng, J.; Wan, X. J. Appl. Toxicol. 2013, 33, 712.

11. Bhattaram, V. A.; Graefe, U.; Kohlert, C.; Veit, M.; Derendorf, H. Phytomedicine 2002, 9 Suppl 3, 1.

12. Kim, Y. H.; Jeong, D. W.; Paek, I. B.; Ji, H. Y.; Kim, Y. C.; Sohn, D. H.; Lee, H. S. J. Chromatogr. B Analyt Technol. Biomed. Life Sci. 2006, 844, 261.

13. Jeong, J. H.; Kim, D. K.; Ji, H. Y.; Oh, S. R.; Lee, H. K.; Lee, H. S. Biomed. Chromatogr. 2011, 25, 879.

14. Ji, H. Y.; Oh, S. R.; Lee, H. K.; Na, D. H.; Lee, H. S. J. Sep. Sci. 2011, 34, 1828.

15. Li, K.; Wang, Y.; Gu, J.; Chen, X.; Zhong, D. J. Chromatogr. B Analyt. Technol. Biomed. Life Sci. 2005, 817, 271.

16. Li, K.; Tang, Y.; Fawcett, J. P.; Gu, J.; Zhong, D. Steroids 2005, 70, 525

17. Wang, B.; Ji, S.; Zhang, H.; Zhao, L.; Lv, L.; Li, Y.; Zhou, G.; Zhang, G. Steroids 2013, doi: 10.1016/j.steroids.2013.08.009. 